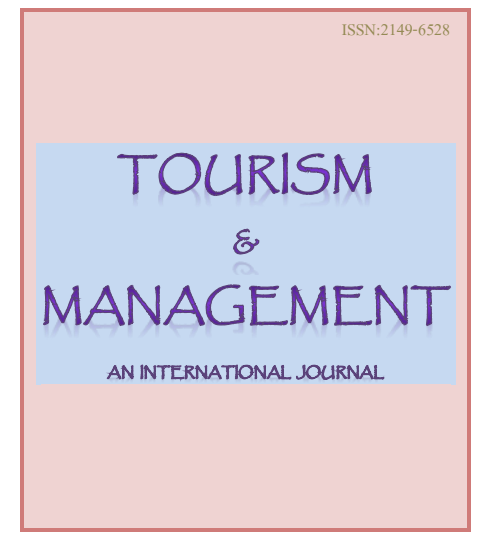

Journal of Tourism\&Management Research ISSN: 2149-6528

\author{
2019 Vol. 4, Issue. 2
}

\title{
A Hybrid Method to Analyze and Manage Tourist Arrivals
}

\begin{abstract}
This paper presents the development of a hybrid methodology to analyze and manage tourist arrivals for identifying the potential of a tourism destination and apperceiving the weaknesses to overcome. The developed Tourist Analysis Management (TAM) methodology integrates safety stock analysis, SWOT (strengths, weaknesses, opportunities and threats) analysis, AHP (analytical hierarchy process), and $\mathrm{ABC}$ analysis to enable a decision maker in determining the tourism carrying capacity of a destination; predicting the number of tourist arrivals; performing strategic planning; and determining optimal strategy plan for tourist arrival management. The developed methodology can be implemented for increasing tourist arrivals in any city. The paper shows its implementation for Agra city, a famous tourist destination of India, in particular. On the basis of historical tourist data, tourism carrying capacity of Agra is determined. Next the strengths, weaknesses, opportunities and threats are identified and are prioritized to formulate strategies. These were then categorized as Vital-Essential-Desirable strategies. The highly rated strategies in context of Agra are improving the reputation of the destination; collecting regular and high quality statistics; ensuring cooperation and coordination among the tourism and other hospitality industries.

Keywords: Tourist arrivals, Strategies, SWOT parameters, Tourism carrying capacity, Tourism management.

JEL Classification: C020; L83; O32

Submitted: 23.02.2019; Accepted: 16.06 .2019

Vijai Dev, PhD. (Corresponding Author). Department of Physics and Computer Science Faculty of Science Dayalbagh Educational Institute (Deemed University) Dayalbagh, Agra - 282005 (India).

Email: Vijay.dev.dei@gmail.com

Preetvanti Singh, PhD. Department of Physics and Computer Science Faculty of Science Dayalbagh Educational Institute (Deemed University) Dayalbagh, Agra - 282005 (India).

Email: preetvantisingh@gmail.com
\end{abstract}




\section{Introduction}

Tourism is a natural human instinct for experience, education and entertainment. It is one of the most dynamic sectors of the global economy, which has accounted for $10.4 \%$ of global gross domestic product, and for 9.9\% of total employment in 2017 (Manzo, 2018). Tourism has become an important sector in the development of a country due to its social, economic, cultural and environmental impact. It has a social significance as it gives importance to community structure, family relationship, collective traditional lifestyles, ceremonies and morality (Pizam and Milman, 1986). Tourism has economic significance as it provides more stable earnings for the country than any other industry (Agaraj and Murati, 2009). Prevention and conservation of culture heritage needs is cultural significance of tourism (Csapo, 2012). It also has environmental significance due to the potential to increase public appreciation of the environment (Sunlu, 2003).

Tourism can also serve as a tool for increasing government revenues and improving residents' quality of life in a destination (Kim et al. 2013). Thus efficient management of tourism becomes essential to attract more tourists at a destination. Tourism management includes the management of tourism products and tourism services (Weiermair, 2000) with the aim of favoring socio-economic progress, ensuring environmental preservation, and satisfying tourists' needs and expectations when they visit the destination.

For effective management of tourism services, it becomes vital to develop a system that can analyze the tourist traffic of a destination, and study the internal and external factors that may affect the performance of this sector. Such a system will help in determining the futuristic trends and making the decision processes of the tourism sector more efficient. Various decision making and management tools can be used to make tourism management more effective.

Analytical Hierarchy Process (AHP) (Saaty, 1987) is a simple, efficient, and structured decision making tool for organizing and analyzing complex decisions which involve comparisons of decision elements that are difficult to quantify. The method starts with creating a pairwise comparison matrix $\mathbf{A}$ which is a $\mathrm{m} \times \mathrm{m}$ real matrix, where $\mathrm{m}$ is the number of evaluation criteria considered. Each entry $a_{j k}$ of the matrix $\mathbf{A}$ represents the importance of the $\mathrm{j}^{\text {th }}$ criterion relative to the $\mathrm{k}^{\text {th }}$ criterion. The relative importance between two criteria is measured according to a numerical scale from 1 to 9 , where it is assumed that the $\mathrm{j}^{\text {th }}$ criterion is equally or more important than the $\mathrm{k}^{\text {th }}$ criterion. Finally, the criteria weight vector $\mathbf{w}$ (an $\mathrm{m}$ dimensional column vector) is built from the matrix $\mathbf{A}$.

SWOT Analysis (Chang \& Huang, 2006) is a strategic planning tool used to evaluate the strengths, weaknesses, opportunities and threats of an organization. The objective of SWOT analysis is to use the knowledge an organization has about its internal and external environments in formulating the strategies for effective management. The internal analysis is used to identify resources, capabilities, core competencies, and competitive advantages inherent to the organization. The external analysis identifies market opportunities and threats by looking at competitors' resources, and the general environment.

ABC analysis (Flores and Whybark, 1986) is a method of analysis that divides the subject into three categories in order of their estimated importance: Category $\mathbf{A}$ represents the most valuable products or customers that contribute heavily to the overall benefit of the organization. Category B represents the middle of the road customers or products, or represents the intermediate position. Category $\mathbf{C}$ represents the least valuable products or customers that do not individually contribute much value to the organization.

Against this backdrop, the current paper focuses on developing a Tourist Arrival Management (TAM) Methodology to identify the potential of a tourism destination and apperceive the weaknesses to overcome. The twofold purpose of the methodology is (a) determine the tourist arrival pattern and (b) eradicate the weakness and threats to encourage 
tourist arrivals at a destination. The proposed methodology is a hybrid method as it combines safety stock analysis, SWOT analysis, AHP, and ABC analysis for analyzing and managing tourist arrivals. The expected outcome of the study helps in analyzing the tourist traffic, and formulating and categorizing strategies.

\section{Literature Review}

\subsection{Analyzing Tourists Arrivals}

Hsu and Wang (2008) employed fuzzy grey model and back-propagation neural networks as the multivariate forecasting models to choose critical influences on tourism demand. Parolo et al. (2009) developed a model for optimizing the allocation of tourist infrastructures based on genetic algorithm to obtain a complex interplay in the form of a dynamical simulation where candidate solutions are interactively evaluated. Kabir et al. (2012) investigated the existing ETourism business models (B2C, B2B, B2B2C) and proposed an optimized a business model G2B2C to promote tourism in developing or under developed countries. Cofas (2014) described and analyzed the circumstances prevailing trends in rural tourism activity in Romania based on the data taken from TEMPO database of the National Institute of Statistics. Akuno et al. (2015) developed a model to forecast tourists' arrival using statistical time series modeling techniques, double exponential smoothing and the auto-regressive integrated moving average. Chang and Chang (2015) developed a tourists' preference model using Fuzzy set theory. Biji et al. (2016) applied statistical methods (territorial series and time series) for analyzing regional tourism in the EU Member States. Faraji Sabokbar et al. (2016) identified risks for a tourism destination of Iran, and discovered the impact of risks by a knowledge base system design. Forecasting risk assessment system was constructed by using fuzzy inference system and dominance-based rough set approach. Fernández-Morales et al. (2016) analyzed seasonality in the United Kingdom in relation to tourists' place of origin and main travel motivation. Xu et al. (2016) developed a tourism demand forecasting method to extract fuzzy Takagi-Sugeno rules from trained support vector machines. The extracted rules exhibited high forecasting accuracy and included understandable pre-condition parts for practitioners.

Reinhold et al. (2017) reviewed and synthesized the explicit use of the business model concept in tourism. Seasonal trend autoregressive integrated moving averages with dendritic neural network model was proposed by $\mathrm{Yu}$ et al. (2017) to perform the tourism demand forecasting. Adeola et al. (2018) estimated a Poisson regression model to determine the key drivers of international tourism demand in 44 African countries over the period 1995-2015. Nor et al. (2018) applied a combination of Box-Jenkins and Artificial Neural Networks to forecast Malaysia's tourism demand. The forecasting performance was assessed by taking each individual method as a benchmark. Rafiei Darani and Asghari (2018) studied and analyzed the determining factors of international tourism demand in Middle Eastern countries using panel data pattern method for data analysis from 1995 to 2013.

\subsection{Managing Tourism}

In order to improve the effectiveness of tourism sector, SWOT Analysis has been performed by researchers as it helps to establish a reliable diagnosis of the internal potential shown by a tourism destination and its environment. Goranczewski and Puciato (2010) identified the role of SWOT analysis in the formulation of tourism development strategies for destinations. Sariisik et al. (2011) analyzed managerial conditions of yacht-tourism in Turkey by conducting a meta-analysis and qualitative view. Zhang (2012) used SWOT analysis to make a comprehensive evaluation and analysis on strengths, weaknesses, opportunities and threats in the development of rural tourism in Suzhou. Sayyed (2013) explored the possibility of sustainable ecotourism development in Tandooreh National Park with reference to judicious 
utilization of resources and local resident community using various decision making tools. Strengths, weaknesses, opportunities and threats were analyzed in order to identify the required management strategies for improving the sustainable tourism in the park. Vladi (2014) prepared marketing strategies with the aim to create and develop Albania's tourism by conducting SWOT analysis.

Mondal and Haque (2017) mapped out a way to sustainable growth of the tourism industry in Bangladesh using the SWOT model and derived a SWOT matrix to formulate strategies for strategic planning. Shafaei and Mohamed (2017) outlined Malaysia's marketing efforts in branding itself as an Islamic tourism hub. SWOT analysis was conducted to summarize the country's internal (strengths and weaknesses) and external (opportunities and threats) issues in branding itself as an Islamic destination. Cetin et al. (2018) designed a framework to evaluate the tourism potential of Yesilyuva Nature Park by using geographic information systems and SWOT analysis. Millan et al. (2018) conducted SWOT analysis for tourism sector, and identified strategic priorities. A series of action guidelines were provided for both public administrations and private initiatives to identify the behaviors and tendencies favorable for rural settings as sustainable spaces for free-time activities in the medium term.

This literature review revealed that methods/algorithms are not developed for analyzing arrival patterns and, on this basis, determining weaknesses and threats to tourist arrivals patterns. Secondly, use of multi-methodology approach can be suitable to deal with different aspects of multi-dimensional tourism management problem.

\section{Methodology}

The focus of the present paper is development of TAM methodology to analyze the tourist arrival pattern and to develop invaluable insights for strategic management decisions. The methodology is developed by integrating safety stock analysis, SWOT analysis, AHP and $\mathrm{ABC}$ Analysis. Integration of these methodologies will enable a decision maker to:

a) determine the tourism carrying capacity of a destination using the modified safety stock analysis;

b) predict the number of tourist arrivals at the destination using regression analysis;

c) find the weaknesses and threats at the destination and perform strategic planning using SWOT analysis. If the predicted tourist arrivals are less than the tourism carrying capacity of the destination, it can be said that the destination is not preferred by the tourists;

d) quantify the importance of SWOT groups and SWOT parameters using AHP; and

e) prioritize strategies to determine optimal strategy plan for tourist arrival management using $\mathrm{ABC}$ analysis.

The applicability of the model is demonstrated by taking Agra as a case study. Agra is a well-known tourist destination of India as it hosts a number of monuments of historical importance, most notably the Taj Mahal, Agra Fort and Fatehpur Sikri.

\subsection{Data Collection}

The tourism data of last 10 years was taken from the official website of Agra tourism. In case to develop strategies for improving the operations of Agra tourism industry, 11 experts were interviewed and literature was reviewed to find the SWOT parameters. A pairwise comparison questionnaire was designed for experts to perform pairwise comparison of the identified SWOT parameters. The rating was done on a 9-point scale (Saaty, 1987). Expert opinions were also considered while categorizing the strategies. 41 tourists (R1), hotel industry stakeholders (R2), academicians (R3), and research scholars (R4) were grouped to form the respondent groups $R^{G},(G=1, \ldots, 4)$. Each of the four respondent groups rated and 
ranked the SWOT parameters using the 9-point scale (Saaty, 1987) that formed the rating matrices.

\subsection{Data Analysis}

The proposed TAM methodology is used to analyze the data. The developed methodology is a flexible and powerful tool as the computations are always guided by the decision maker's experience that enables to translate the evaluations (both qualitative and quantitative) made by the decision maker into a multi-criteria ranking. The methodology also provides information that is helpful in matching the organization's capabilities to the competitive environment in which it operates by identifying strengths and opportunities which are helpful to achieve the organizational objectives; and weaknesses and threats that are harmful to achieve the organizational objectives. The methodology revolves around the expert group and the respondent group. The computation framework is shown in Figure 1. The phase-wise description of the method is as follows:

Phase I: Analyze tourism carrying capacity and predict the tourist arrivals;

1. On the basis of the historical tourism data, analyze the annual tourist arrival $\left(A_{T}\right)$

2. Determine tourism carrying capacity of a city $\left(C_{T}\right)$ for the time period $N+1$

$$
C_{T}=A_{T}+\left(A_{V}+S_{L}\right)
$$

Where $A_{V}$ is the Arrival Variability, given as:

$$
A_{V}=\sqrt{\frac{\left(A_{T}-T_{N}\right)^{2}}{N}}
$$

$T_{N}$ is tourist arrival in $\mathrm{N}$ years and $S_{L}$ is the surplus arrival specified by Z-Scores.

3. Perform trend analysis for tourist arrivals and predict the tourist arrivals using the regression model.

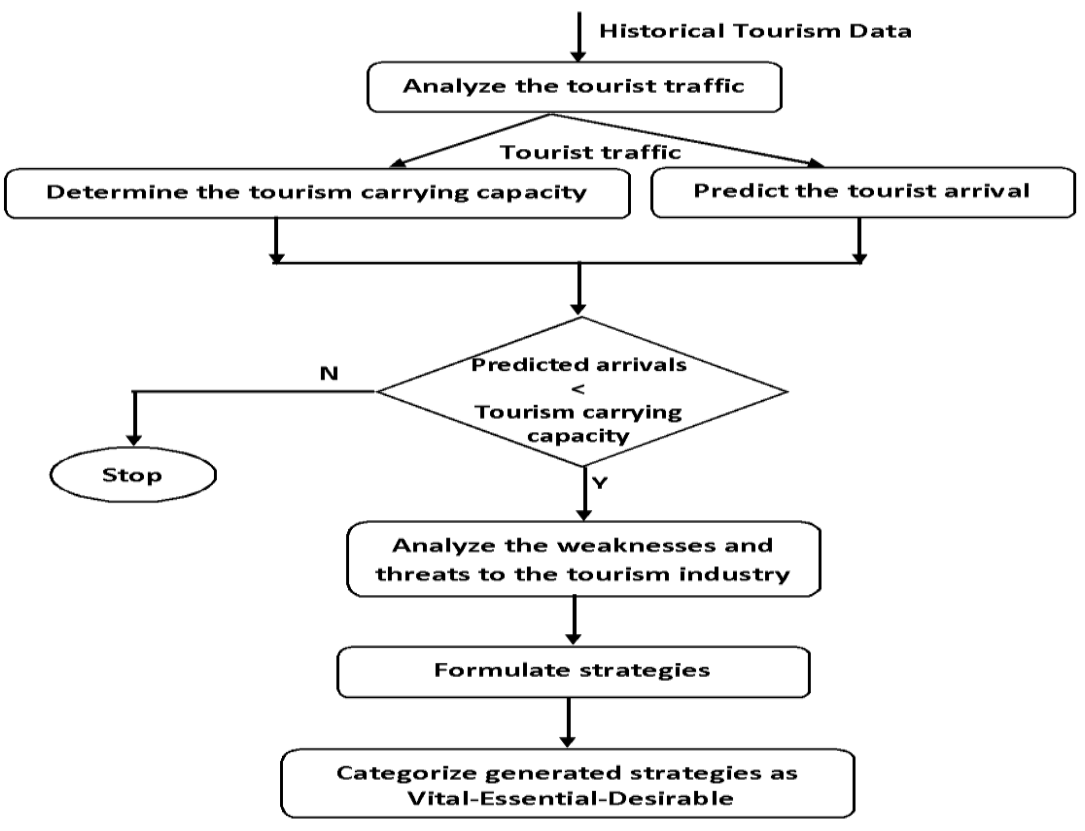

Figure 1: The TAM methodological framework.

Source: Author Survey 
Phase II: Perform SWOT Analysis and determine vital-essential-desirable strategies;

1) Identify strengths, weaknesses, opportunities, and threats for tourism industry. Rate and rank the respondent groups $\left(R^{G}, G=1, \ldots, g\right)$.

2) Compute Respondent-Importance Weight $\left(R I_{W}^{G}\right)$ for the respondent group using the pairwise comparison matrices.

3) Perform the pairwise rating and ranking of SWOT group and SWOT parameters.

4) Calculate Parameter Importance weights from the rating and ranking of the SWOT group $\left(P G^{W}\right)$ and the SWOT parameters $\left(P I^{W}\right)$.

5) Compute Priority weights using the equations given below to determine the prioritized SWOT group $\left(P_{S}^{W}\right)$ and SWOT parameters $\left(\operatorname{Pr}_{S}^{W}\right)$

$$
\begin{aligned}
& P_{S}^{W}=\frac{1}{g} \sum_{G=1}^{g}\left(R I_{w}^{G} \times P G^{W}\right) \\
& P r_{S}^{W}=\frac{1}{g} \sum_{G=1}^{g}\left(R I_{w}^{G} \times P I^{W}\right)
\end{aligned}
$$

6) Calculate Overall Priority Weights $\left(O_{S}^{W}\right)$ for the parameters as

$$
O_{S}^{W}=P_{S}^{W} \times P r_{S}^{W}
$$

7) Design TWOS Matrix to generate the strategies.

8) Categorize the formulated strategies as vital-essential-desirable (V-E-D) strategies.

\subsection{Computational Experience}

On the basis of historical tourist data, annual tourist arrivals and tourism carrying capacity is computed as explain in Steps 1 and 2 above. The tourist arrival in the city is predicted using following the regression models:

$$
\begin{array}{ll}
\text { Domestic Tourists } & \mathrm{y}=747557 \mathrm{x}+3 \mathrm{E}+06 \\
\text { Foreign Tourists } & \mathrm{y}=97366 \mathrm{x}+697060
\end{array}
$$

It was observed that the predicted arrival is less than the tourism carrying capacity of Agra. The reason of this may be improper management of the tourism industry. Thus proceed to Phase II of the Methodology to generate TWOS matrix on the basis of computed $O_{S}^{W}$, and formulate and categorize the strategies.

\section{Results}

Using the historical tourism data, the average tourist arrivals for domestic and foreign tourists is given in I column of Table 1. Yearly arrivals are shown in Figure 2 and Figure 3 respectively. Maximum domestic tourist arrivals were in the year 2015 which decreased in the following years. However, there is an increasing trend for the arrival of the foreign tourist. Second column of Table 1 shows the accommodating capacity of tourists in Agra city for foreign as well as domestic tourists. It can be seen that although there is an increasing trend amongst the foreign tourists, still the number of foreign tourists is very less as compared to domestic tourist. Third column of this table depicts that the arrivals in 2018 for domestic tourists is decreasing. 
Table 1: Tourist arrival at Agra city.

\begin{tabular}{cccccc}
\hline \multicolumn{2}{c}{\begin{tabular}{c} 
Annual Tourist Arrivals \\
\multicolumn{2}{c}{ (In lakh) }
\end{tabular}} & \multicolumn{2}{c}{ Tourism Carrying Capacity } & \multicolumn{2}{c}{ Predicted Arrivals } \\
& (For the Year 2018, in lakh) & (For the Year 2018, in lakh) \\
\hline Domestic & Foreign & Domestic & Foreign & Domestic & Foreign \\
$71.73 \pm 22.20$ & $11.83 \pm 2.80$ & $108.37-108.36$ & $16.46-16.45$ & 104.76 & 16.71 \\
\hline
\end{tabular}

Source: Agra Tourism (2017).

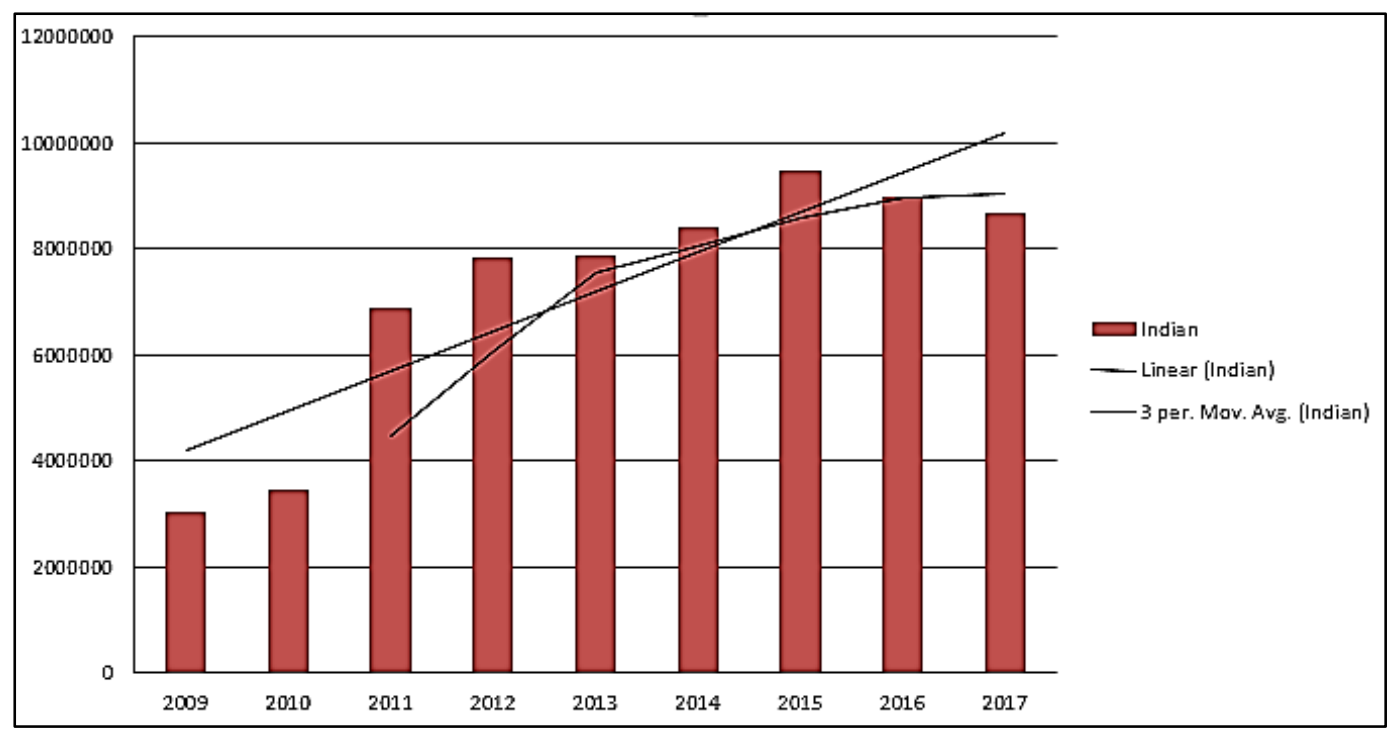

Figure 2: Tourist Arrivals in Agra (Domestic).

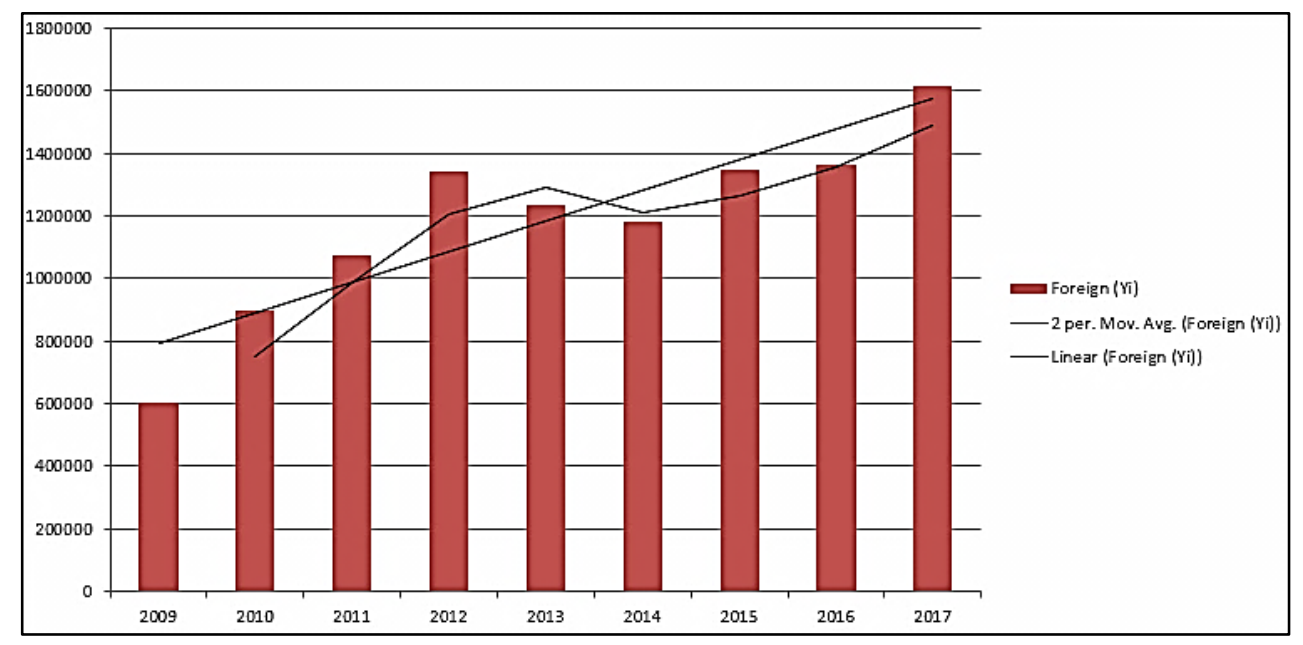

Figure 3: Tourist arrivals (Foreign).

The literature review and the expert opinion resulted in the identified SWOT parameters for efficient tourist arrival management at Agra and are listed in Table 2. 
Table 2: SWOT parameters.

\begin{tabular}{|c|c|c|}
\hline & $\begin{array}{l}\text { Helps } \\
\text { (To achieve the objectives of tourism } \\
\text { industry) }\end{array}$ & $\begin{array}{l}\text { Harms } \\
\text { (In achieving the objectives of tourism industry) }\end{array}$ \\
\hline \multirow{10}{*}{ 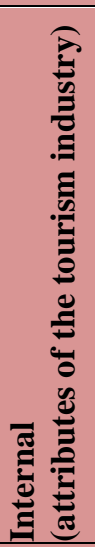 } & Strengths & Weaknesses \\
\hline & S1: Tourist spots of historical importance & W1: Lack of appropriate educational programs \\
\hline & S2: Shopping facilities & W2: Behavior of people at tourist spots \\
\hline & S3: Rich Biodiversity & W3: Inaccessibility to tourist spots \\
\hline & S4: Rich cultural diversity & W4: Security and safety at tourism destinations \\
\hline & S5: Skilled workforce & W5: No empathy for tourists \\
\hline & S6: Existence of tour operators & $\begin{array}{l}\text { W6: Working of associated (combined) sectors (like } \\
\text { hotels, transport) independently }\end{array}$ \\
\hline & S7: Accommodations and dining facilities & W7: Lack of regular and high quality statistics \\
\hline & $\begin{array}{l}\text { S8: Niche tourism products like heritage, } \\
\text { culture, medical, education, and pilgrim } \\
\text { destination }\end{array}$ & W8: Maintenance and Cleanliness \\
\hline & & W9: Lapke, Begging and Cheating \\
\hline \multirow{10}{*}{ 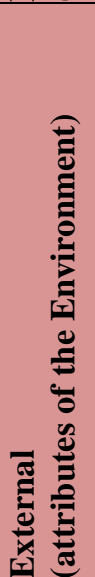 } & Opportunities & Threats \\
\hline & $O 1:$ Courses in foreign languages & T1: High competition from nearby cities \\
\hline & $\begin{array}{l}\text { O2: Training programs for hospitality } \\
\text { sectors }\end{array}$ & T2: Socio-cultural degradation due to local people \\
\hline & O3: Technically trained tourism staff & T3: Lack of diversification in tourism product \\
\hline & $\begin{array}{l}\text { O4: Development of tourist circuits across } \\
\text { the states }\end{array}$ & T4: Higher travel cost \\
\hline & O5: Booming ICT & T5: Environmental damage \\
\hline & $\begin{array}{l}\text { O6: Potential to improve niche tourism } \\
\text { products }\end{array}$ & T6: Damage to monuments \\
\hline & O7: Entry of multinational companies & $\begin{array}{l}\text { T7: Higher cost of accommodation, food and local } \\
\text { travel }\end{array}$ \\
\hline & O8: Fully serviced accommodation & T8: Unregulated infrastructure development \\
\hline & & T9: Reputation of the location \\
\hline
\end{tabular}

The SWOT groups, parameters, and developed strategies are organized in a hierarchical structure as shown in Figure 4, where at the top most level is the goal, followed by the SWOT groups and parameters, which will be used in formulating the SO, WO, ST and WT strategies.

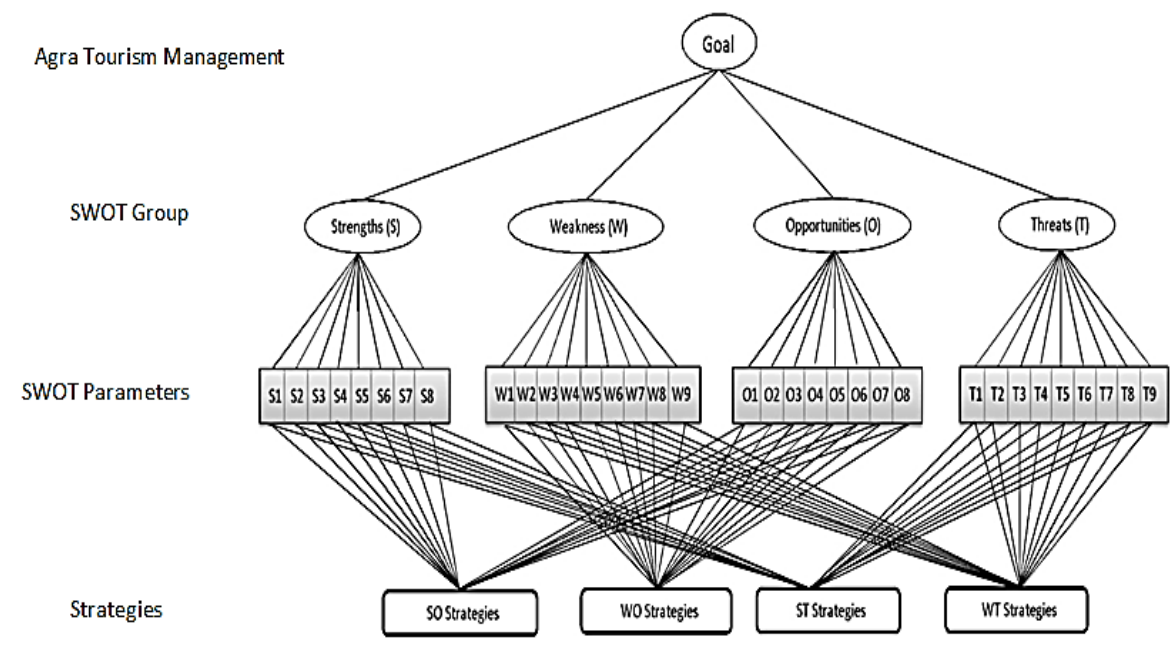

Figure 4: Hierarchical structure of SWOT parameters. 
The respondents groups $\mathrm{R} 1, \mathrm{R} 2, \mathrm{R} 3$, and $\mathrm{R} 4$ were rated to determine the $R I_{w}^{G}$ as illustrated in Table 3.

Table 3: Relative rating of respondents' group.

\begin{tabular}{llllcc}
\hline & $\mathbf{R 1}$ & $\mathbf{R 2}$ & $\mathbf{R 3}$ & $\mathbf{R 4}$ & $\mathbf{R I}_{\boldsymbol{w}}^{\boldsymbol{G}}$ \\
\hline $\mathbf{R 1}$ & 1 & 1 & 4 & 6 & 0.377 \\
$\mathbf{R 2}$ & & 1 & 4 & 7 & 0.379 \\
$\mathbf{R 3}$ & & & 1 & 4 & 0.139 \\
$\mathbf{R 4}$ & & & & 1 & 0.106 \\
\hline
\end{tabular}

The rating matrices were used to determine $P I_{w}^{G}$ for the SWOT parameters. A sample rating matrix is displayed in Table 4.

Table 4: Rating of SWOT parameters (particularly for strengths).

\begin{tabular}{|c|c|c|c|c|c|c|c|c|c|}
\hline & S1 & S2 & S3 & S4 & S5 & S6 & S7 & S8 & $P I_{w}^{G}$ \\
\hline S1 & 1.00 & 1.00 & 0.11 & 4.00 & 5.00 & 1.00 & 0.33 & 4.00 & 0.139 \\
\hline S2 & & 1.00 & 5.00 & 5.00 & 1.00 & 0.50 & 0.17 & 3.00 & 0.117 \\
\hline S3 & & & 1.00 & 1.00 & 0.50 & 0.20 & 0.33 & 0.33 & 0.108 \\
\hline S4 & & & & 1.00 & 0.33 & 0.17 & 0.20 & 0.20 & 0.030 \\
\hline S5 & & & & & 1.00 & 0.20 & 0.33 & 2.00 & 0.075 \\
\hline S6 & & & & & & 1.00 & 1.00 & 4.00 & 0.212 \\
\hline S7 & & & & & & & 1.00 & 6.00 & 0.251 \\
\hline S8 & & & & & & & & 1.00 & 0.068 \\
\hline
\end{tabular}

The priority weights for each of the SWOT group $\left(P G^{W}\right)$ and the SWOT parameters $\left(P I^{W}\right)$, and Overall Priority Weights $\left(O_{S}^{W}\right)$ for the SWOT parameters were computed as explained in Step 4 through Step 6 of the methodology. The computed $\operatorname{Pr}_{S}^{W}$ weights and the $O_{S}^{W}$ Weights for the parameters are shown in Table 5.

Table 5: Priorities for SWOT groups and SWOT parameters.

\begin{tabular}{l|c|l|l|l}
\hline $\begin{array}{l}\text { SWOT } \\
\text { Parameters }\end{array}$ & $\boldsymbol{P}_{\boldsymbol{S}}^{W}$ & SWOT Parameters & $\boldsymbol{P r}_{\boldsymbol{S}}^{W}$ & $\boldsymbol{O}_{\boldsymbol{S}}^{\boldsymbol{W}}$ \\
\hline Strengths & 0.427 & S1: Tourist spots of historical importance & 0.296 & 0.1264 \\
& & S2: Shopping facilities & 0.080 & 0.0342 \\
& & 0.061 & 0.026 \\
& & S3: Rich Biodiversity & 0.195 & 0.0833 \\
& & S4: Rich cultural diversity & 0.026 & 0.0111 \\
& & S5: Skilled workforce & 0.022 & 0.0094 \\
\hline
\end{tabular}




\begin{tabular}{|c|c|c|c|c|}
\hline & & $\begin{array}{l}\text { S7: Accommodations and dining facilities } \\
\text { S8: Niche tourism products like heritage, } \\
\text { culture, medical, education, and pilgrim } \\
\text { destination }\end{array}$ & $\begin{array}{l}0.090 \\
0.229\end{array}$ & $\begin{array}{l}0.0384 \\
0.0978\end{array}$ \\
\hline Weaknesses & 0.165 & $\begin{array}{l}\text { W1: Lack of appropriate educational } \\
\text { programs } \\
\text { W2: Behavior of people at tourist spots } \\
\text { W3: Inaccessibility to tourist spots } \\
\text { W4: Security and safety at tourism } \\
\text { destinations } \\
\text { W5: No empathy for tourists } \\
\text { W6: Working of associated (combined) } \\
\text { sectors (like hotels, transport) independently } \\
\text { W7: Lack of regular and high quality statistics } \\
\text { W8: Maintenance and Cleanliness } \\
\text { W9: Lapke, Begging and Cheating }\end{array}$ & $\begin{array}{l}0.151 \\
0.154 \\
0.081 \\
0.088 \\
0.154 \\
0.057 \\
0.138 \\
0.086 \\
0.091\end{array}$ & $\begin{array}{l}0.0249 \\
0.0254 \\
0.0134 \\
0.0145 \\
0.0254 \\
0.0094 \\
0.0228 \\
0.0142 \\
0.0150\end{array}$ \\
\hline Opportunities & 0.225 & $\begin{array}{l}\text { O1: Courses in foreign languages } \\
\text { O2: Training programs for hospitality sectors } \\
\text { O3: Technically trained tourism staff } \\
\text { O4: Development of tourist circuits across the } \\
\text { states } \\
\text { O5: Booming ICT } \\
\text { O6: Potential to improve niche tourism } \\
\text { products } \\
\text { O7: Entry of multinational companies } \\
\text { O8: Fully serviced accommodation }\end{array}$ & $\begin{array}{l}0.138 \\
0.149 \\
0.149 \\
0.139 \\
0.138 \\
0.13 \\
0.073 \\
0.084 \\
\end{array}$ & $\begin{array}{l}0.0311 \\
0.0335 \\
0.0335 \\
0.0313 \\
0.0311 \\
0.0293 \\
0.0164 \\
0.0189 \\
\end{array}$ \\
\hline Threats & 0.183 & $\begin{array}{l}\text { T1: High competition from nearby cities } \\
\text { T2: Socio-cultural degradation due to local } \\
\text { people } \\
\text { T3: Lack of diversification in tourism product } \\
\text { T4: Higher travel cost } \\
\text { T5: Environmental damage } \\
\text { T6: Damage to monuments } \\
\text { T7: Higher cost of accommodation, food and } \\
\text { local travel } \\
\text { T8: Unregulated infrastructure development } \\
\text { T9: Reputation of the location }\end{array}$ & $\begin{array}{l}0.141 \\
0.143 \\
0.044 \\
0.089 \\
0.092 \\
0.090 \\
0.078 \\
0.095 \\
0.228\end{array}$ & $\begin{array}{l}0.0258 \\
0.0262 \\
\\
0.081 \\
0.0163 \\
0.0168 \\
0.0165 \\
0.0143 \\
0.0174 \\
0.0417\end{array}$ \\
\hline
\end{tabular}

These prioritized parameters formed the TWOS matrix (see Table 6) which helped in formulating SO, WO, ST and WT strategies. The experts formulated eight strategies under four conceptually distinct strategic groups (SO, WO, ST, WT) of TOWS matrix. The TOWS matrix (Weihrich, 1982) is used to develop strategies based on logical combinations of factors related to internal strengths (or weaknesses) with parameters related to external opportunities (or threats).

The strategies identified as SO concerns making good use of opportunities by using the existing strengths. The WO strategies seek to reduce internal weaknesses by taking advantage of external opportunities. The ST strategies are related to utilize the strengths in order to avoid or reduce the effects of threats. Finally, the WT strategies aim to reduce the effects of threats and weaknesses. 
Table 6: The TWOS Matrix with formulated strategies.

\begin{tabular}{|c|c|c|}
\hline External Factors & $\begin{array}{l}\text { Internal Factors } \\
\text { Strengths } \\
\text { S1: Tourist spots of historical } \\
\text { importance } \\
\text { S2: Shopping facilities } \\
\text { S3: Rich Biodiversity } \\
\text { S4: Rich cultural diversity } \\
\text { S5: Skilled workforce } \\
\text { S6: Existence of tour } \\
\text { operators } \\
\text { S7: Accommodations and } \\
\text { dining facilities } \\
\text { S8: Niche tourism products } \\
\text { like heritage, culture, } \\
\text { medical, education, and } \\
\text { pilgrim destination }\end{array}$ & $\begin{array}{l}\text { Weaknesses } \\
\text { W1: Lack of appropriate } \\
\text { educational programs } \\
\text { W2: Behavior of people at } \\
\text { tourist spots } \\
\text { W3: Inaccessibility to tourist } \\
\text { spots } \\
\text { W4: Security and safety at } \\
\text { tourism destinations } \\
\text { W5: No empathy for tourists } \\
\text { W6: Working of associated } \\
\text { (combined) sectors (like hotels, } \\
\text { transport) independently } \\
\text { W7: Lack of regular and high } \\
\text { quality statistics } \\
\text { W8: Maintenance and } \\
\text { Cleanliness } \\
\text { W9: Lapke, Begging and } \\
\text { Cheating }\end{array}$ \\
\hline $\begin{array}{l}\text { Opportunities } \\
\text { O1: Courses in foreign languages } \\
\text { O2: Training programs for } \\
\text { hospitality sectors } \\
\text { O3: Technically trained tourism } \\
\text { staff } \\
\text { O4: Development of tourist circuits } \\
\text { across the states } \\
\text { O5: Booming ICT } \\
\text { O6: Potential to improve niche } \\
\text { tourism products } \\
\text { O7: Entry of multinational } \\
\text { companies } \\
\text { O8: Fully serviced accommodation }\end{array}$ & 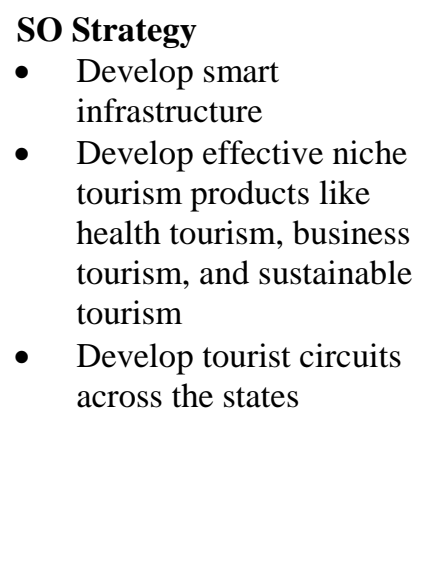 & $\begin{array}{l}\text { WO Strategy } \\
\text { - Collect regular and high } \\
\text { - } \quad \text { Enality statistics } \\
\text { coordination among the } \\
\text { tourism, and other } \\
\text { hospitality industries } \\
\text { - Implement educational } \\
\text { programs for tourism sector }\end{array}$ \\
\hline $\begin{array}{l}\text { Threats } \\
\text { T1: High competition from nearby } \\
\text { cities } \\
\text { T2: Socio-cultural degradation due } \\
\text { to local people } \\
\text { T3: Lack of diversification in } \\
\text { tourism product } \\
\text { T4: Higher travel cost } \\
\text { T5: Environmental damage } \\
\text { T6: Damage to monuments } \\
\text { T7: Higher cost of accommodation, } \\
\text { food and local travel } \\
\text { T8: Unregulated infrastructure } \\
\text { development } \\
\text { T9: Reputation of the location }\end{array}$ & $\begin{array}{l}\text { ST Strategy } \\
-\quad \text { Promote eco-tourism }\end{array}$ & $\begin{array}{l}\text { WT Strategy } \\
\text { - Improve the reputation of } \\
\text { the destination }\end{array}$ \\
\hline
\end{tabular}


On the basis of experts and tourists feedback, these strategies were categorized as VitalEssential-Desired. The categorized strategies are illustrated in Figure 5. Out of the formulated 8 strategies, 3 were rated vital (Category A), 3 were essential (Category B) and 2 were rated desirable (Category C) by the experts.

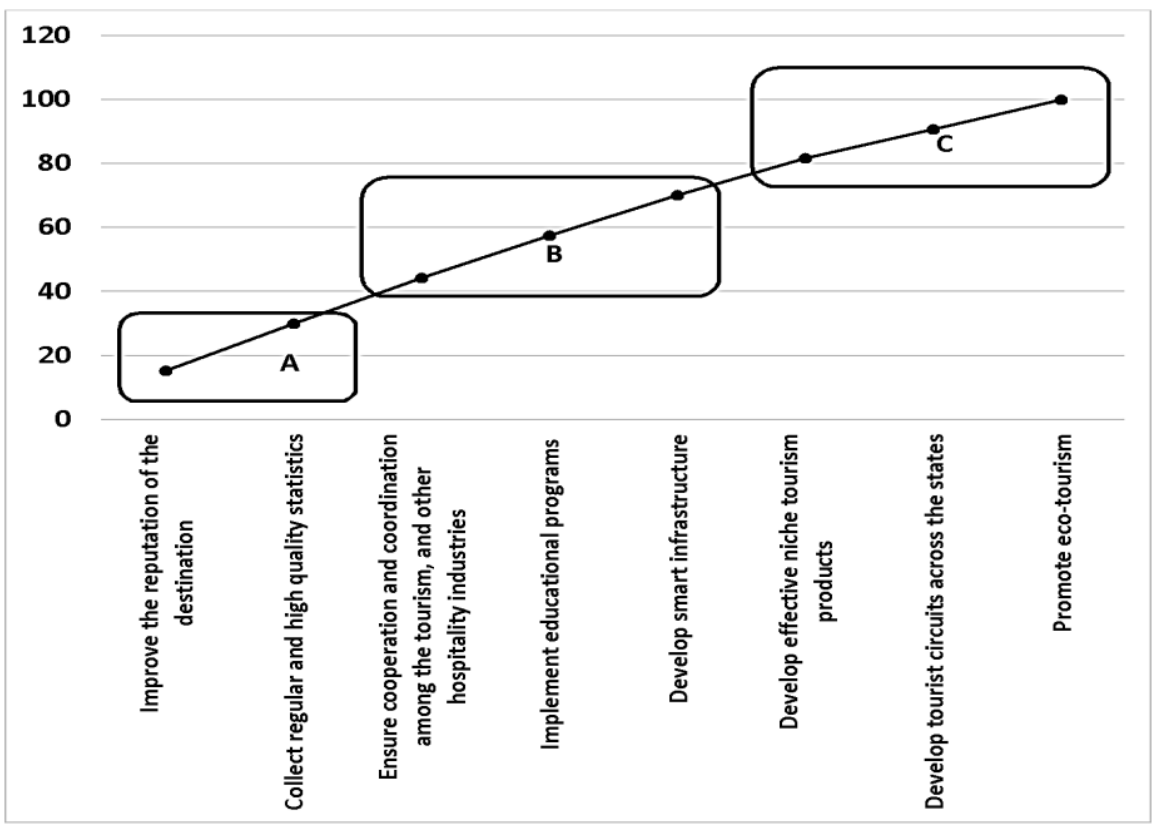

Figure 5: Categorized strategies.

Thus in context of Agra, the strategies that need to be implemented at the earliest are

1) Improve the reputation of the destination;

2) Collect regular and high quality statistics; and

3) Ensure cooperation and coordination among the tourism, and other hospitality industries.

It is also essential to implement educational programs for tourism sector, develop smart infrastructure and develop effective niche tourism products.

The two strategies, developing tourist circuits across the states and promote eco-tourism, although are not rated very important, but, if implemented, can further enhance the management of tourist arrivals in the city.

\section{Conclusion, Implications and Limitations}

Tourism, as a global economic activity, favors socio-economic progress within those territories where it is developed. There are multiple positive effects derived from tourism such as the creation of jobs, its capability to fix the population to the territory, or its ability to diversify agricultural production in certain areas. For an increasing number of countries, tourism represents a strategic sector that is to be supported and protected through adequate legislation and infrastructure investments. Various tourism management problems in a tourist destination like traffic congestion, energy consumption, air pollution and traveler delay are explore in literature. However, analysis of tourist arrival pattern followed by management of tourist arrivals is not discussed much in literature.

This paper is an effort to analyze the tourist traffic and then suggest strategies to enhance the tourist arrival management. The focus of the study is to develop a new research methodology, the TAM methodology, by combining the advantages of safety stock analysis, 
SWOT analysis, AHP, and ABC analysis for achieving the goal. The developed methodology can be used for decision making in complex scenario, where decision makers' work together to make decisions when human perceptions, judgments, and consequences have long term repercussions. Its power lies in assigning the rankings that are obtained on the basis of the pairwise relative evaluations of both, the criteria and the options provided by the user. The benefits of the methodology are that it

- takes into account all important criteria which can be organized into a hierarchy;

- imitates the way human thinks about the decision making;

- uses both quantitative and qualitative attributes/criteria;

- checks consistency in the judgment;

- determines the trade-offs among criteria;

- performs strategic planning based on its internal and external environment; and

- determines optimal strategy. The optimal strategy among multiple strategies can be defined as the strategy with high performance on identified internal and external factors.

The real life implementation of the methodology is given by taking Agra, a famous tourist destination of India, as a case study. On the basis of historical tourist data, tourism carrying capacity is determine and tourist arrival is predictive.

Next the strengths, weaknesses, opportunities and threats are identified and rated to derive prioritized SWOT parameters, which were then used to formulate strategies. These formulated strategies are finally categorized as Vital-Essential-Desirable strategies. The three highly rated strategies for augmenting Agra tourism are

- Improve the reputation of the destination;

- Collect regular and high quality statistics; and

- Ensure cooperation and coordination among the tourism, and other hospitality industries.

Actions plan must be immediately generated for the above strategies and implemented by the policy makers to increase the tourist arrivals at Agra. The proposed methodology thus can be helpful for the tourism stakeholders as it is capable of determining tourism carrying capacity of a destination and then enabling the decision makers to formulate strategies through environmental scanning for internal and external factors that may affect the performance of the tourism industry.

The limitations of the methodology are: firstly, tourism products like hotels, markets etc. can also be considered while predicting the arrivals. Secondly, the tourism data for the foreign tourists was not considered country-wise, which could further help in focusing on continentwise preferences of the tourists arriving at a destination.

\section{References}

Adeola, O., Boso, N. and Evans, O. (2018). Drivers of international tourism demand in Africa. Business Economics, 53(1), 25-36.

Agaraj, X. and Murati, M. (2009). Tourism an important sector of economy development. Annals-Economy Series, 183-90.

Agra Tourism. (2017). http://www.uptourism.gov.in. Accessed 01 January, 2017.

Akuno, A. O., Otieno, M. O., Mwangi, C. W. and Bichanga, L. A. (2015). Statistical models for forecasting tourists' arrival in Kenya. Open Journal of Statistics, 5(01), 60-65.

Biji, E. M., Lilea, E., Vatui, M. and Rosca, E. R. (2016). Statistical analysis of the regional tourism development in the European Union. The USV Annals of Economics and Public Administration, 15(2-22) 188-199. 
Cetin, M., Zeren, I., Sevik, H., Cakir, C. and Akpinar, H. (2018). A study on the determination of the natural park's sustainable tourism potential. Environmental monitoring and assessment, 190(3), 167 1-8.

Chang, H. H. and Huang, W. C. (2006). Application of a quantification SWOT analytical method. Mathematical and Computer Modeling, 43(1-2), 158-169.

Chang, J. R. and Chang, B. (2015). The development of a tourism attraction model by using fuzzy theory. Mathematical Problems in Engineering, 1-10.

Cofas, E. (2014). Models for the statistical analysis of trends in rural tourism activity in Romania. International Journal of Academic Research in Environment and Geography, 1(2), 18-25.

Csapo, J. (2012). The role and importance of cultural tourism in modern tourism industry. In Strategies for tourism industry-micro and macro perspectives. Dr. Murat Kasimoglu (Ed.), ISBN: 978-953-51-0566-4, IntechOpen, 201-232.

Faraji Sabokbar, H., Ayashi, A., Hosseini, A., Banaitis, A., Banaitienè, N. and Ayashi, R. (2016). Risk assessment in tourism system using a fuzzy set and dominance-based rough set. Technological and Economic Development of Economy, 22(4), 554-573.

Fernández-Morales, A., Cisneros-Martínez, J. D. and McCabe, S. (2016). Seasonal concentration of tourism demand: Decomposition analysis and marketing implications. Tourism Management, $56,172-190$.

Flores, B. E., and Whybark, D. C (1986). Multiple criteria ABC analysis. International Journal of Operations \& Production Management, 6(3), 38-46.

Goranczewski, B. and Puciato, D. (2010). SWOT analysis in the formulation of tourism development strategies for destinations. Tourism, 20(2), 45-53.

Hsu, L. C. and Wang, C. H. (2008). Applied multivariate forecasting model to tourism industry. Turizam: međunarodni znanstveno-stručni časopis, 56(2), 159-172.

Kabir, M. A., Jahan, K., Adnan, M. N. and Khan, N. (2012). Business model of e-tourism for developing countries. International Journal of Computer and Information Technology, 3(1), 30-34.

Kim, K., Uysal, M. and Sirgy, M. J. (2013). How does tourism in a community impact the quality of life of community residents?. Tourism management, 36, 527-540.

Manzo, G. G. (2018). Travel \& Tourism Economic Impact 2018 World, World Travel \& Tourism Council: https://www.wttc.org/-/media/files/reports/economic-impact-research/ regions-2018/world2018.pdf. Accessed 15 May 2017.

Millan, G., Amador, L. and Arjona, J. (2018). Sustainable rural tourism in Andalusia: A SWOT analysis. International Journal of Advances in Management and Economics, 123-136.

Mondal, M., and Haque, S. (2017). Swot analysis and strategies to develop sustainable tourism in Bangladesh. UTMS Journal of Economics, 8(2), 159-167.

Nor, M. E., Nurul, A. I. and Rusiman, M. S. (2018). A Hybrid Approach on Tourism Demand Forecasting. Journal of Physics: Conference Series, 995(1), 12-34.

Parolo, G., Ferrarini, A. and Rossi, G. (2009). Optimization of tourism impacts within protected areas by means of genetic algorithms. Ecological Modelling, 220(8), 11381147.

Pizam, A. and Milman, A. (1986). The social impacts of tourism. Tourism Recreation Research, 11(1), 29-33.

Rafiei Darani, H. and Asghari, H. (2018). Study of international tourism demand in Middle East by panel data model. International Journal of Culture, Tourism and Hospitality Research, 12(1), 80-88.

Reinhold, S., Zach, F. J. and Krizaj, D. (2017). Business models in tourism: a review and research agenda. Tourism Review, 72(4), 462-482. 
Saaty, T. L. (1987). A New Macro Economic Forecasting and Policy Evaluation Method using the Analytic Hierarchy Process. Mathematical Modelling, 9(3-5), 219-232.

Sariisik, M., Turkay, O. and Akova, O. (2011). How to manage yacht tourism in Turkey: A swot analysis and related strategies. Procedia-Social and Behavioral Sciences, 24 10141025.

Sayyed, M. R. G. (2013). SWOT analysis of Tandooreh National Park (NE Iran) for sustainable ecotourism. Proceedings of the International Academy of Ecology and Environmental Sciences, 3(4), 296-305.

Shafaei, F. and Mohamed, B. (2017). Malaysia's branding as an Islamic tourism hub: An assessment. Geografia-Malaysian Journal of Society and Space, 11(1), 97-106.

Sunlu, U. (2003). Environmental impacts of tourism. In Camarda D. (ed.), Grassini L. (ed.). Local resources and global trades: Environments and agriculture in the Mediterranean region. Bari : CIHEAM, 263-270.

Vladi, E. (2014). Tourism Development Strategies, SWOT analysis and improvement of Albania's image. European Journal of Sustainable Development, 3(1), 167-178.

Weiermair, K. (2000). Tourists' perceptions towards and satisfaction with service quality in the cross-cultural service encounter: implications for hospitality and tourism management. Managing Service Quality: An International Journal, 10(6), 397-409.

Weihrich, H. (1982). The TOWS matrix-A tool for situational analysis. Long range planning, 15(2), 54-66.

Xu, X., Law, R., Chen, W. and Tang, L. (2016). Forecasting tourism demand by extracting fuzzy Takagi-Sugeno rules from trained SVMs. CAAI Transactions on Intelligence Technology, 1(1) 30-42.

Yu, Y., Wang, Y., Gao, S. and Tang, Z. (2017). Statistical modeling and prediction for tourism economy using dendritic neural network. Computational intelligence and neuroscience, $1-9$.

Zhang, X. (2012). Research on the development strategies of rural tourism in Suzhou based on SWOT analysis. Energy Procedia, 16, 1295-1299.

\section{Author Biography}

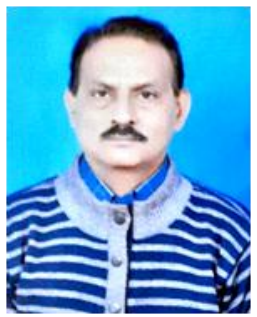

Vijai Dev is a Ph.D. student in Department of Physics and Computer Science, Faculty of Science at Dayalbagh Educational Institute, Dayalbagh, Agra, India. His research interests include Data Warehouse, RDBMS and ORDBMS. Currently he has published various refereed articles for tourism management and planning.

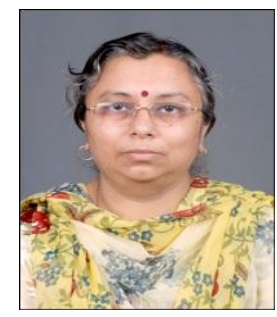


Preetvanti Singh is at present Professor (Computer Science) in the Department of Physics and Computer Science, Dayalbagh Educational Institute. Her research areas are Operations Research, Decision Support System, and Data Mining. She has published research papers in various international journals like EJOR, APJOR, etc. and has authored 3 books. 